\title{
Initiation of Olefin Metathesis: Reaction of Deca-2,8-diene with Catalysts formed from $\mathrm{Me}_{4} \mathrm{Sn}-\mathrm{WCl}_{6}$ and $\mathrm{Me}_{3} \mathrm{Al}_{2} \mathrm{Cl}_{3}-\left(\mathrm{Ph}_{3} \mathrm{P}\right)_{2}(\mathrm{NO})_{2} \mathrm{Cl}_{2} \mathrm{Mo}$
}

\author{
By Robert H. Grubbs* and Charles R. Hoppin \\ (Department of Chemistry, Michigan State University, East Lansing, Michigan 48824)
}

Summary The initial product of the metathesis of deca2,8-diene with metathesis catalysts formed from either $\mathrm{Me}_{4} \mathrm{Sn}-\mathrm{WCl}_{6}$ or $\mathrm{Me}_{3} \mathrm{Al}_{2} \mathrm{Cl}_{3}-\left(\mathrm{Ph}_{3} \mathrm{P}\right)_{2}(\mathrm{NO})_{2} \mathrm{Cl}_{2} \mathrm{Mo}$ is propene; labelling of the terminal groups of the diene and the alkylating agents gives a labelling pattern in the propene that is best explained in terms of generation of a carbene in the initiation step from the alkylating agent.

THE olefin metathesis reaction has provided one of the major mechanistic challenges in transition metal organic chemistry. ${ }^{1}$ All the data to date are most consistent with a chain reaction involving odd carbon intermediates, with the reaction in Scheme 1 being the most reasonable propagation step. ${ }^{2}$ The major homogeneous catalyst systems are

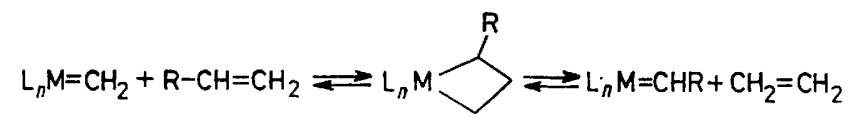

SCHEME 1

prepared from a tungsten-, molybdenum-, or rheniumhalide complex and an alkyl-aluminium or -tin co-catalyst. Although there are models for the initiation step (metalalkylidene complex formation) in such systems ${ }^{3}$ there is little evidence for the initiation mode ${ }^{4}$ in these catalysts. Different initiation modes have been proposed for other types of catalysts. ${ }^{5}$ Schrock has shown that tantalumalkylidene complexes can be formed by the reaction of tantalum halides with alkyl lithium reagents (Scheme 2). ${ }^{3 \mathrm{a}}$

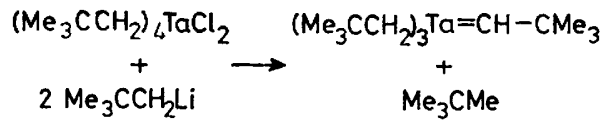

SCHEME 2

We now have good evidence that carbenoid species are formed in alkylaluminium-molybdenum complex ${ }^{6}$ and alkyltin-tungsten complex catalyst systems. ${ }^{7}$ Mixing of the transition metal complex with the appropriate methyltin or -aluminium cocatalyst results in the formation of methane and ethylene [equations (1) and (2)]. The products produced by using $\left(\mathrm{CD}_{3}\right)_{4} \mathrm{Sn}$ were perdeuteriated.

$$
\begin{aligned}
\mathrm{Mo}\left(\mathrm{Ph}_{3} \mathrm{P}\right)_{2} \mathrm{Cl}_{2}(\mathrm{NO})_{2}+\mathrm{Me}_{3} \mathrm{Al}_{2} \mathrm{Cl}_{3} \stackrel{\mathrm{PhCl}}{\longrightarrow} \mathrm{CH}_{4} \\
+\mathrm{CH}_{2}=\mathrm{CH}_{2}+\text { Mo-catalyst }
\end{aligned}
$$

$\mathrm{WCl}_{6}+\mathrm{Me}_{4} \mathrm{Sn} \stackrel{\mathrm{PhCl}}{\longrightarrow} \mathrm{CH}_{4}+\mathrm{CH}_{2}=\mathrm{CH}_{2}+$ W-catalyst

When deca-2,8-diene (I) was mixed with the catalyst solution, the initial product was propene in both cases followed by the production of the usual products [equation (3)].

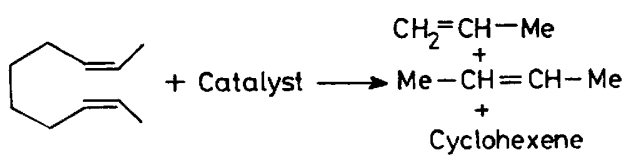

(I)

When the reactions were repeated with $[1,1,1,10,10,10-$ $\left.{ }^{2} \mathrm{H}_{6}\right]$ deca-2,8-diene, the product was $\left[3,3,3-{ }^{2} \mathrm{H}_{3}\right]$ propene; reactions of $\left(\mathrm{CD}_{3}\right)_{4} \mathrm{Sn}-\mathrm{WCl}_{6}$ with (I) gave $\left[1,1-{ }^{2} \mathrm{H}_{2}\right]$ propene and of $\left[{ }^{2} \mathrm{H}_{6}\right]-(\mathrm{I})$ with $\left(\mathrm{CD}_{3}\right)_{4} \mathrm{Sn}-\mathrm{WCl}_{6}$ gave $\left[1,1,3,3,3-{ }^{2} \mathrm{H}_{5}\right]-$ propene as the initial product.

These results, combined with the model studies, ${ }^{3}$ provide a mechanism for initiation which is consistent with the labelling pattern $\left(*\right.$ and $\left.{ }^{* *}\right)$ shown in Scheme 3.

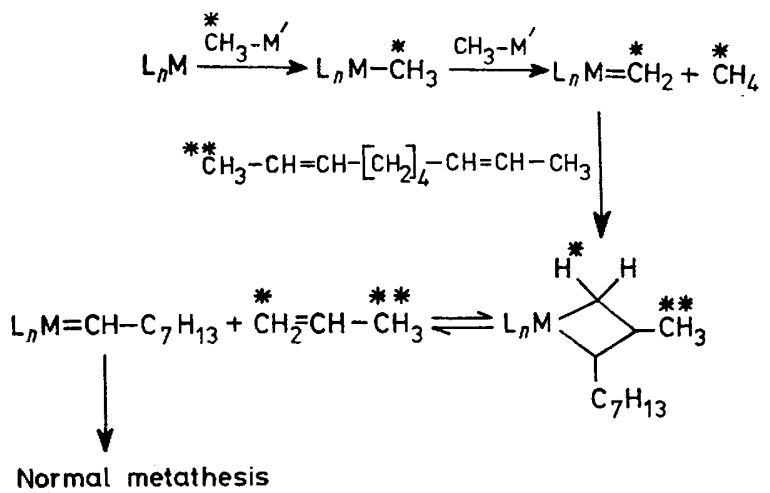

SCheme 3

These experiments provide information concerning two other aspects of the reaction. The yield of propene based on the amount of transition metal indicates the percentage converted into the active catalyst in the initiation step. The molybdenum system is much more active for metathesis than the $\mathrm{WCl}_{6}-\mathrm{SnMe}_{4}$ system and produces a much higher yield of propene $(c a .90 \%$ compared to $8 \%$ ). The production of ethylene, apparently by metal carbene 
dimerization during the initiation, indicates one of the chain termination mechanisms; methylene-metal complexes have been found to dimerize ${ }^{3}$ according to equation (4).

$$
2 \mathrm{~L}_{n} \mathrm{M}=\stackrel{*}{\mathrm{C}} \mathrm{H}_{2} \rightarrow \stackrel{*}{\mathrm{C}} \mathrm{H}_{2}=\stackrel{*}{\mathrm{C}} \mathrm{H}_{2}
$$

This labelling study provides considerable information concerning the initiation, activity, and termination of the methathesis reaction.

1 N. Calderon, A. Ofstead, and W. A. Judy, Angew. Chem. Internat. Edn., 1976, 15, 401; R. H. Grubbs, 'New Applications of Organometal Reagents in Organic Synthesis,' ed. D. Seyferth, 1976, p. 423.

2 R. H. Grubbs, D. D. Carr, C. Hoppin, and P. L. Burk, J. Amer. Chem. Soc., 1976, 98, 3478; T. J. Katz and J. McGinnis, ibid., 1977, 99, 1903, and references therein; P. G. Gassman and T. H. Johnson, ibid., 1976, 98, 6055, 6057, 6058.

${ }^{3}$ (a) R. R. Schrock, J. Amer. Chem. Soc., 1975, 97, 6577; (b) C. P. Casey, T. J. Burkhardt, C. A. Bunnell, and J. C. Calabase, ibid., $1977,99,2127$, and references therein.

4 E. L. Muetterties, Inorg. Chem., 1975, 14, 951.

5 M. F. Farona and W. S. Greenlee, J.C.S. Chem. Comm., 1975, 859; P. Krausz, F. Garnier, and J. E. Dubois, J. Amer. Chem. Soc., $1975,97,437 ; \mathrm{R}$. Westnoff and J. A. Moulin, J. Catalysis, 1977, 46, 414.

B. E. A. Zeuch, Chem. Comm., 1968, 1182.

7 P. B. Van Dam, M. C. Mittelmeijer, and C. Boelhouwer, J.C.S. Chem. Comm, 1972, 1221. 